\title{
COMMENTS ON "BEDROCK INTENSITY ATTENUATION AND SITE FACTORS FROM SAN FERNANDO EARTHQUAKE RECORDS" BY K. W. CAMPBELL AND C. MARTIN DUKE
}

\author{
By Paul C. Jennings
}

In the paper "Bedrock Intensity Attenuation and Site Factors from San Fernando Earthquake Records," by K. W. Campbell and C. Martin Duke, which appeared in the February, 1974 issue of the Bulletin, a correlation is made between a measure of intensity of recorded ground accelerations and four categories of soil, classified by increasing softness. The authors present different numerical site factors for each category and conclude that their results are sufficiently reliable to justify their use for purposes of zoning. The site factors and the conclusion are based mainly on the data presented in their Figure 5 and the lines of specified slope fitted by least squares to the data points. The set of lines in their Figure 6 present the authors' idealized relation between intensity, softness of ground, and distance from the source. The upper four lines in Figure 6 are taken from Figure 5 .

The idealized set of lines shown in Figure 6 could be misleading if used for purposes of zoning, as illustrated by the following comparisons based on the data points shown in Figure 5. In Figure 5a, which is included with this communication, the line fitted by the authors to the data points for site classification 2 (sedimentary rock) has also been drawn as a dashed line through the other three sets of data. The dashed lines clearly fit the data points for site classifications 3 (shallow alluvium) and 4 (deep alluvium) very well. For site classification 1 (basement rock), the dashed line does not fit well the data points for distances greater than 30 miles, but at distances less than 30 miles the dashed line fits the data points as well as the solid line fitted by the authors. Considering only the data points for distances less than 30 miles, which are the distances of greatest significance for engineering, the "best fit" line for site classification 1 would lie about halfway between the dashed line and the solid line. It is not clear, however, whether differences among the solid line, dashed line and a "best fit" line for distances less than 30 miles, have either statistical or physical significance.

A distance of 30 miles from the center of the San Fernando earthquake extends well south of downtown Los Angeles, southeast to Pasadena, and beyond Lancaster to the north, so that practically all significant damage during the San Fernando earthquake is included within this distance. For this region of damaging motion the single dashed line fits the data points, for practical purposes, as well as do the four solid lines fitted by the authors. This indicates that any effect of softness of ground according to the authors' classification, if it exists, is more or less concealed by the wide scatter of the data points. The scatter of the data in Figure 5 is so large that numerical use of the idealized set of lines in Figure 6 for purposes of zoning could give an unjustified impression of precision. The agreement of all four sets of data to a single line, for distances less than 30 miles, could be improved further by using a line with a slope somewhat different from that assumed by the authors.

The goodness of fit of the line for site classification 2 to data points for site classifications 3 and 4 indicates that there is not a significant effect of softness of ground for these categories. For site classification 1 the data points at distances greater than 30 miles from the source have lower values than those for site classifications 2,3 and 4 , which might be significant, although additional data would be desirable before concluding this. However, 
the values of the intensities at these larger distances are so small that the practical significance of any influence of the ground is small.

The writer also questions the use of the hypothetical concept of the intensity of motion on an "outcrop of unweathered, unfractured basement complex" and the use of
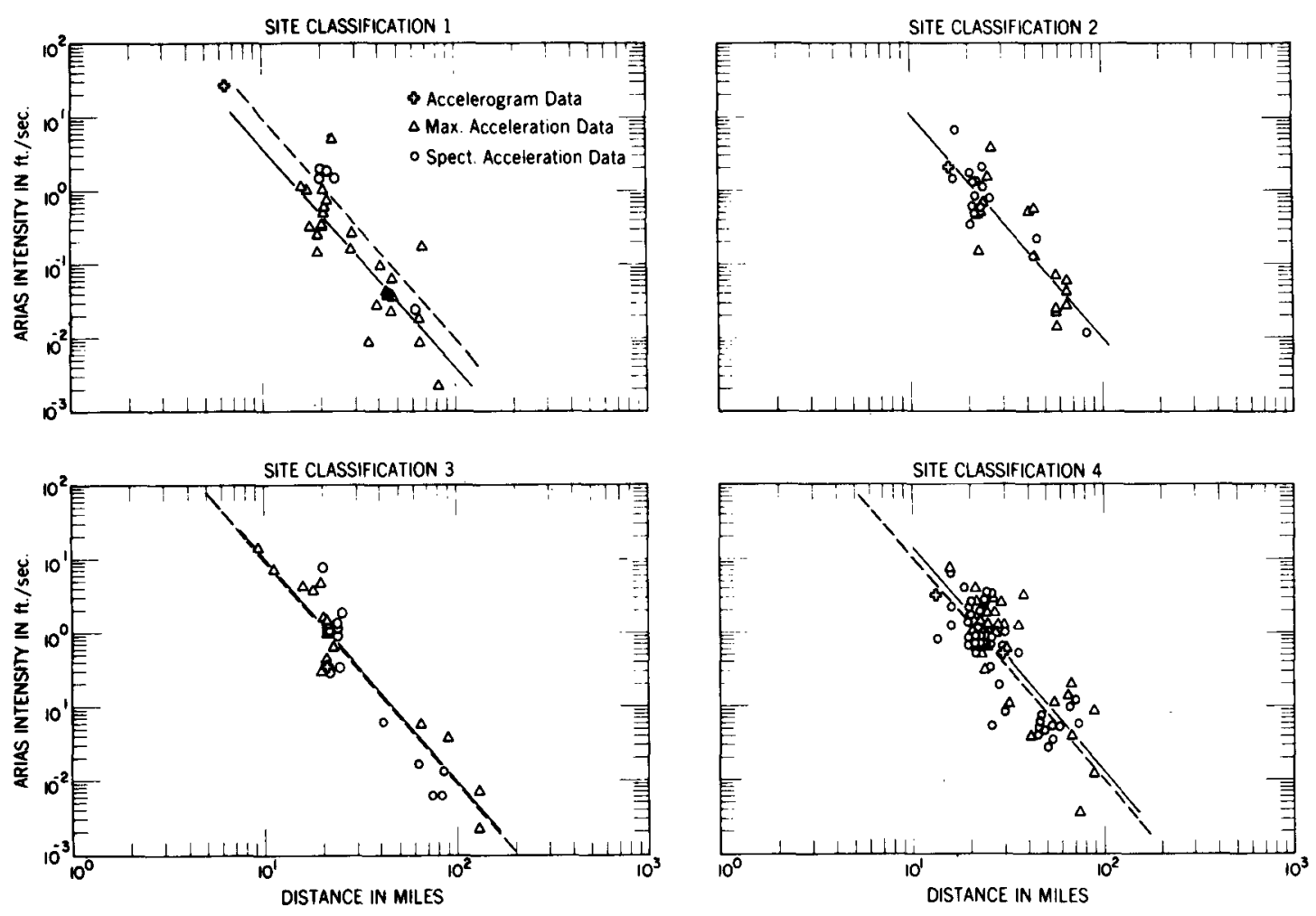

FIG. 5a. Modified version of Figure 5 of the paper "Bedrock Intensity Attenuation and Site Factors from San Fernando Earthquake Records" by K. W. Campbell and C. Martin Duke (1974). Bull. Seism. Soc. Am. 64, 173-185.

this intensity for the base of the site factors given in the paper. The level of this hypothetical motion, the lower curve in Figure 6, is primarily a consequence of a series of assumptions regarding the propagation of waves, the attenuation value $Q$, and the shearwave velocity. Other investigators, should they choose to use this concept, would almost certainly arrive at different results and the differences could not be resolved by direct measurement of surface motions.

EARTHQUAKE ENGINEERING RESEARCH LABORATORY

California Institute of TechNology

Pasadena, California 91109

Manuscript received May 1, 1974 